\title{
E-Waste as Perceived by Different World Economies: Critical Review of Literature
}

\author{
Virginia Onyara $(\mathbf{P h D})$
}

Multimedia University of Kenya

ABSTRACT

This article outlines how different world economies define e-waste. It further looks at how the narratives coming from these definitions affect the scope of management of e-waste. Geographical and social-economic dynamism does affect similarities and differences in approaches to the management of e-waste. As much as each geographical location defines $e$ waste in its own familiar context and peculiarity, several definitions have major components left out or added, creating strengths or weaknesses for each one of them. Each definition on its own uniquely shows the regional integration in thought and how diverse it is in beliefs of what are uniquely them. This article sums up by showing how an aspect of e-waste management disposal, has predicted how economies define e-waste and why there is need to understand different contextual definitions for different world economies so as to effectively manage electrical and electronic equipment once they reach their end of life in the context of the user. The study identifies factors that have aided disposal of e-waste, these factors include; legal and regulatory frameworks, e-waste concept, availability and affordability of the EEE. This study considers Disposal of EEE as a determinant measure of e-waste definition.

Key Words: E-waste, Concepts, Electrical and Electronic Equipment, End of Life

DOI: $10.35942 /$ ijcab.v4i1.106

\section{Cite this Article:}

Onyara, V. (2020). E-Waste as Perceived by Different World Economies: Critical Review of Literature. International Journal of Current Aspects, 4(1), 33-42. https://doi.org/10.35942/ijcab.v4i1.106

\section{Introduction}

Words in a definition can mean different things at different times. A definitions main aim is to communicate meaning for users to understand (Unified Compliance, 2020). A good definition contains many different, essential characteristics. For example, in defining words, the definition should not contain examples, it must capture precisely the essence of what is being defined, and must not use more complex terms than the definition itself (Veerasamy, 2013). Words come into existence to express thoughts by a group of people that share them, at a point in time, with a meaning that reflects their origin, use, and timeframe. Language is alive and keeps growing, technology keeps growing, and so words that define technology and its growth will quite often also grow. As man grows in thought and deeds, language also grows and the vocabulary keeps expanding. It is because of the differences in presentation, context and scope that similar concepts or items may have different definitions.

Electronic waste or e-waste is one such emergent word that has come up due to progress in technology and innovation. E-waste has been defined differently by the users of the term depending on the user's perspective. (EU, 2012; Step Initiative, 2019; US EPA, 2014; NEMA, 
2013; Republic of Rwanda, 2016; UCC, 2018). All the definitions for different users have a definitive unified approach for people that share similar socio-economic and cultural practices. Also, different world economies have defined e-waste differently from their perception of what e-waste is. Socio-economic gains have had a hand in how definitions for different economies are drawn. There are many reasons that determine how and why people dispose e-waste the way they do. Several factors have aided disposal of e-waste, these factors include; legal and regulatory frameworks, e-waste concept and availability and affordability of the electrical and electronic equipment (EEE). In developed economies, disposal mechanisms are advanced (EU, 2012). There are blueprints that can guide users as they plan to dispose of their discarded equipment. For example, one can give the waste of electrical and electronic equipment (WEEE) to official collection points for further disposal.

In emerging economies, lack of awareness on what WEEE is, is a major challenge, users hold on to the equipment for as long as they can, partly because of the value they attach to the equipment or out of utter ignorance of e-waste material composition some of which are hazardous to human health and the environment (WHO, 2020) and therefore are not keen on how to dispose it of separately from other types of waste. Most organizations have no e-waste disposal plans (Koloseni \& Shimba, 2012). Insufficient drop off points for citizens to dispose the end of life (EOL) equipment and lack of awareness on how and why they should be disposed of separately from other waste streams are some of the factors affecting how the masses in developing countries dispose of the waste.

\section{Research Problem}

Electronic and electrical equipment (EEE) especially the information and communication technology (ICT) equipment are growing rapidly around the globe. Technology is becoming more and more integrated into every aspect of human lives. Although they provide many countless benefits to the consumers, EEE are considered hazardous to human life and the environment once they reach their end of life (ITU, 2019; WHO, 2020). Latest estimates from the International Telecommunication Union (ITU) and United Nations University (UNU) study show that the world now discards approximately 50 million metric tonnes (Mt) of e-waste per year and only $20 \%$ is recycled. In 2016 , over $35 \mathrm{Mt}$ was not documented, it is presumed it was being either discarded in landfill, burned or illegally traded and treated in a sub-standard way (Baldé, et al., 2017). E-waste contains hazardous substances, including mercury, cadmium and lead, which can end up polluting land, air and water, thus posing health risks, especially if treated inadequately. On the other hand, e-waste could present an opportunity worth over 62.5 billion dollars per year if treated through appropriate e-waste handling methods, with the potential of creating millions of decent new 'clean and green' jobs worldwide (ITU, 2019).

The EU, developed the WEEE directive, which provides for the creation of collection schemes allowing consumers to return WEEE free of charge (EU, 2012). There is no federal law in the U.S. that mandates the recycling of e-waste or forbids e-waste from being exported to developing countries. Less than 30 states have their own electronic recycling laws, which vary in approach (Schumacher, 2016). Some states authorize companies to operate a statewide collection system while others require manufacturers to meet minimum recycling targets based on their sales. Most of the state laws are generally based on the concept of extended producer responsibility. Here, electronics manufacturers are responsible for a product through its end-of-life treatment, and manufacturers are often required to pay for a contractor to manage statewide collection and recycling of WEEE. 
In many developing countries, the challenges facing e-waste management include: absence of infrastructure for appropriate e-waste management, absence of e-waste legislation, absence of any framework for EOL product take-back or implementation of extended producer responsibility (EPR) (Mmereki et al., 2015; Vaccari et al., 2019; Basel Convention, 2011). The absence of such critical tools of management has curtailed any efforts at all levels of its management. Most importantly, it has affected how consumers in developing nations dispose their WEEE. Effective disposal of e-waste by the consumer of EEE depends on the availability of the e-waste, willingness of the user to dispose it, availability of disposal mechanisms, infrastructure for the treatment of WEEE and enforcement of the legal tools. In the absence of such determinants there may be little or no achieved results.

\section{Critical Review of Literature}

\subsection{Definition of e-waste}

So far there are so many different definitions of e-waste. There is no mutually agreed standard definition of e-waste but different entities have attempted to define the term. Largely, e-waste is the term used to cover all types of electronic and electric equipment (EEE) that has or could enter the waste stream (Mbago, 2018). E-waste is a general term that covers any household or business item with circuitry or electrical components with power or battery supply. These may consist of EEE and accessories that are non-operational. EEE include; computers, televisions, audio-visual recorders, mobile phones, printers and other electronic goods such as air conditioners, electronic toys, washing machines, sewing machines, lawn mowers, elevators, kitchen equipment, therapeutic and hospital equipment, surveillance equipment, mobile radio transmitters, refrigerators, and their accessories etc.

\subsection{E-waste as defined by different world economies}

There are discrepancies in the way world economies define WEEE. Different world economies whether developed or developing perceive e-waste differently. The differences in the definitions range from technological advances, ability to manufacture and generate it and consumer purchasing power. For example, Solving the e-waste problem Initiative (Step Initiative, 2019) defines electronic waste, or e-waste, as all electrical and electronic equipment and its parts that have been discarded by its owner as waste without the intent of reuse. Step Initiative looks at ALL types of EEE and its parts "discarded by the OWNER without the intent of reuse". This definition works very well in economies where technologies keep changing and consumers have to keep upgrading their EEE especially Information Communication Technology (ICT) devices, to remain relevant. In this case once the OWNER of EEE discards it, without the intent to reuse, it is considered as WEEE. This implies that the item has no further use and is rejected as useless or excess to the owner in its current condition.

The European Union (EU) WEEE directive (2012) defines e-waste as electrical or electronic equipment waste that includes all components, subassemblies, and consumables that are part of the product at the time of discarding. This definition by the EU directive considers it prudent to have the words components, subassemblies and consumables added to the definition, and is silent on who discards the WEEE. Unlike the Step Initiative definition which is clear about the EEE being discarded by the owner as waste, WEEE directive looks at the EEE and all its components, subassemblies and consumables but does not mention who discards it. Later in the WEEE directive other e-waste treatment directives are given but the definition is silent on who 
disposes the WEEE, probably because it is expected to be general knowledge to the citizens and the omission is no error.

United States of America (US) considers e-waste, e-scrap and end-of-life electronics as terms often used to describe used electronics that are nearing the end of their useful life, and are discarded, donated or given to a recycler (US EPA, 2014). According to the US environmental Protection Agency (EPA) e-waste is a subset of used electronics. They recognize the inherent value of these materials that can be reused, refurbished or recycled to minimize the actual waste that might end up in a landfill or improperly disposed in an unprotected dump site, they therefore define e-waste or e-scrap as used electronics that are nearing the end of their useful life, and are discarded, donated or given to a recycler. This definition by the US brings in the idea of the EEE not having reached its EOL but considers those that are nearing the end of 'useful' life. The definition recognizes that the EEE may have some other values which are essential to other processes once recovered. For example, it mentions that, you can discard, donate or give to a recycler to recover materials or for final disposal. It looks beyond disposing and tries to check how the final disposal of the WEEE will be done once the materials are reused, refurbished, or recycled. In the definition they suggest ways to dispose the WEEE. According to Basel Action Network (BAN, 2019), there is lack of adherence to international waste trade rules by some unscrupulous US recyclers to export many hundreds of containers of hazardous electronic waste each week to developing countries for so-called recycling. This realization might have necessitated the introduction of donating and giving the e-waste to the recycler to be included in their definition.

Kenya's National Environment Management Authority (NEMA) defines e-waste as waste resulting from electrical and electronic equipment including components and assemblies thereof (NEMA, 2013), this definition by Kenya is closely similar to the definition given by the EUs WEEE directive; It mentions components and subassemblies but is quiet on consumables which form part of the e-waste. Kenya, like any other emerging economies does not manufacture or produce EEE, but assembles parts of the EEE. The country ships in equipment parts or panels and assemble them for local use (Daily Nation, 2013). The government has also engaged local universities to assemble EEE especially computers for use by schools (Business Daily, 2019). This could be partly the reason why components and subassemblies were included in the definition, to cater for the unique aspect of locally assembling of EEE.

Uganda Communications Commission (UCC), a Telecoms and ICT regulator in Uganda defines e-waste as all discarded and disposed of EEE assemblies, scrap components and batteries (UCC, 2018). Uganda's definition is quite interesting because it introduces scrap components and batteries. The two are given prominence in the definition probably because Uganda manufactures automotive batteries, solar batteries, and mixed acid batteries (UBL, 2020). A report by Enclude (2014) shows that in 2009 an estimated 1.1 MW of solar PV power was installed nationwide in Uganda, that means Uganda heavily depends on solar for energy and this could be the reason why batteries are predominantly placed in the definition so as to cater for the off grid solar products once they reach their end of useful life.

Existing literature on e-waste in Tanzania shows that the country has no specific policy or regulation related to e-waste management (Koloseni \& Shimba, 2012). There are a number of regulations and laws that provides an institutional framework for a sustainable management of the environment in general, the Environmental Management Act (EMA) No. 20 of 2004 is the fundamental legislation that guides the management of e waste in Tanzania. In the Act, e-waste 
is considered as part of hazardous waste. Undocumented information by Tanzania environmental management experts reveals that the country defines e-waste as waste resulting from EEE, whole or in part or rejects from their manufacturing and repair process which are intended to be discarded. This definition talks about the whole EEE, in part or rejects which are to be discarded. Tanzania mentions EEE that have been rejected during manufacturing process and also talks of EEE repair processes in its definition. The Republic of Rwanda (2016) defines e-waste as all discarded and disposed EEE. They define EEE as equipment dependent on electric currents or electromagnetic fields (EMF) in order to work properly, and also any equipment used for the generation, transfer and measurement of such currents and fields. Rwanda in their definition of EEE mentions equipment used for generation, transfer and measurement of electric currents and field.

Table 1: A Comparison of e-waste definitions for different world economies

\begin{tabular}{|l|l|}
\hline Examples of definitions by developed economies & Examples of definitions by Emerging economies \\
\hline $\begin{array}{l}\text { Step initiative (2014) } \\
\begin{array}{l}\text { All electrical and electronic equipment and its parts } \\
\text { that have been discarded by its owner as waste } \\
\text { without the intent of reuse }\end{array}\end{array}$ & $\begin{array}{l}\text { NEMA Kenya (2013) } \\
\text { and assemblies thereof }\end{array}$ \\
\hline $\begin{array}{l}\text { EU WEEE Directive (2012) } \\
\text { electrical or electronic equipment waste that includes } \\
\text { all components, subassemblies, and consumables that } \\
\text { are part of the product at the time of discarding }\end{array}$ & $\begin{array}{l}\text { UCC (2018) } \\
\text { scrap components and batteries }\end{array}$ \\
\hline $\begin{array}{l}\text { US EPA (2014) } \\
\text { describe used electronics that are nearing the end of } \\
\text { their useful life, and are discarded, donated or given } \\
\text { to a recycler }\end{array}$ & $\begin{array}{l}\text { Republic of Rwanda (2016) } \\
\text { all discarded and disposed EEE }\end{array}$ \\
\hline
\end{tabular}

The definition above pass the criteria for a good definition as mentioned earlier, e.g. none of the definitions contain examples, they all capture precisely the essence of what e-waste is and lastly all of them do not use complex language to define the term e-waste. A closer look at the definitions, however, indicates that in defining e-waste or WEEE, countries have emphasized different things that affect them as countries or regions. What is available in-country A may not be available in-country B because of the dynamics of each country in terms of socio-economic, technological and cultural activities of the people. Some countries are manufacturers of EEE and so may put more emphasis on processes and products, others are consumers, and their emphasis would be on usage. Importantly, all definitions talk about disposal. Whether the owner discards the product or not, it is considered WEEE when it is disposed of. Disposal of EEE, therefore, could be considered as a determinant measure of e-waste definition.

\subsection{Disposal as a determinant of e-waste definition}

Disposal and collection of WEEE go hand in hand. Once the user/owner or an entity disposes the WEEE it is collected by e-waste handlers and sent for treatment. The WEEE directive shows 
clearly how the disposal and collection of WEEE should be done in the EU. Each Member State of the EU is required to ensure the implementation of the producer responsibility principle and, on that basis, should ensure that a minimum collection rate is achieved annually (EU, 2012). There is no federal law in the U.S. that mandates the recycling of e-waste; states have set up ewaste collection points where consumers can drop off unwanted items. In emerging economies, disposal of e-waste is still at its infancy stage. There are no precise mechanisms of how disposal and collection should be done. Owners of WEEE still hold on to their EOL equipment because of either sentimental value attached to the equipment or hope that a miracle might happen and the 'dead' equipment will find value again or they simply have no idea where to dispose the equipment once it reaches EOL, they dispose it in landfills thus posing health and environmental challenges. Most of the disposed e-waste is handled by the informal sector who only pick components that are important to them and their operations and dispose the remaining parts to landfills. Several factors have aided disposal of e-waste, these factors include; legal and regulatory frameworks, e-waste concept and availability and affordability of the EEE.

\subsection{Legal and Regulatory Framework}

Developed economies have matured legal instruments that help in the management of EEE. They have both mandatory and voluntary instruments that they use to manage e-waste. In the European Union (EU), for example, e-waste management is regulated by the WEEE Directive (2012/19/EU). The Directive is meant to regulate the collection, recycling, and recovery of ewaste. It includes the provision of national e-waste collection points and processing systems, which enable the proper disposal and treatment of e-waste (EU, 2012). The Directive requires Member States to create systems that allow final stakeholders and distributors to return e-waste free of charge. To guarantee the environmentally sound treatment of the separately collected ewaste, this legal framework uses the principle of Extended Producer Responsibility (EPR), which requires producers to organize and/or finance the collection, treatment, and recycling of their products at end-of-life. In Europe, there are voluntary e-waste certification standards e.g. the European Electrotechnical Committee for Standardization (CENELEC), WEEE Label for Excellence (WEEELABEX) and the US has the following voluntary certification standards; Repair and Recycling (R2), Electronic Product Environmental Assessment Tool (EPEAT) Standards, e-Stewards (SIMS LTD, 2019) and many others still being developed which ensures that e-waste is collected, transported and treated following the set requirements.

In developed economies, where systems work and regulations are fully developed and enforced the implementation of the Extended Producer Responsibility (EPR) and take back systems are adhered to. This makes it possible for the citizens of those countries to dispose of their EEE once they feel they need to either upgrade the equipment and or the EEE has reached its EOL and needs to be discarded. Once the equipment reaches its EOL, the owner can take it back to the manufacturer or retailer for an upgrade or final disposal. Also, in an EPR programme, the collector has no worry of breaking even in his business since the collection of WEEE just like the other processes of WEEE treatment have already been paid for upfront by the manufacturers/producers of EEE. Under the EPR policy approach, producers are given a significant financial and or physical responsibility for the treatment or disposal of post-consumer products (OECD, 2019). Assigning such responsibility could in principle provide incentives to prevent wastes at the source. Again, in such economies it is easier for the owners to dispose of the equipment because the take-back system is workable and enforced. 
In developing economies, where e-waste regulations and other legal instruments are still being developed or not yet developed, proper take-back systems have not been realized, and many countries have not been able to implement the EPR programme. Many developing countries do not have such plans where e-waste handlers can do their job without thinking about how they will get finances for the activities they undertake because they are confident the producers have paid for the treatment of generated wastes. Lack of a proper take back system for consumers and an efficient EPR scheme for e-waste handlers makes it difficult for owners of EEE to properly dispose of their discarded WEEE. This could be the reason why some countries insist in their definition that there must be the willingness to dispose it off for it to become e-waste. In developed economies, discarding of EEE is done with ease because disposal mechanisms are fully developed; once the EEE becomes WEEE there are clear instructions of how it should be discarded. Regulations on management of EEE are clear and enforceable. Most developing nations have no clear regulations or guidelines on how management of WEEE and most specifically how the disposal of WEEE should be done, There is insufficient enforceable and voluntary regulatory framework to help in management of e-waste (EACO, 2017).

\subsection{E-waste concept}

Developed economies have had the e-waste concept for a long time, however, the need for the proper disposal of that electronic waste began in the mid-70s (Stream Recycling, 2018). Besides manufacturing the EEE, they already envisioned the entire circularity of the product. The whole life cycle of the product from ideation to its EOL is considered as part of the process of production. This has been figured out and better ways of handling EOL devices still being studied. E-waste is a new concept in many parts of emerging economies. Most emerging economies do not manufacture EEE and so have no say in how the products they consume should be. In some instances, countries lack technology, infrastructure, and expertise required to treat WEEE (EACO, 2017). Many consumers of electrical EEE in developing economies have their own descriptions of what they consider to be e-waste. Some have no idea when the EEE currently in use will reach its end-of-life. Once the equipment stops working, they keep them in storage for as long as they can, hoping that they will be reused and be of value to them again. Due to technological advances, availability and affordability of the same EEE in its superior form; the old one will never find itself in use again. Some users will gift their families and friends or donate the EEE to users who may need them.

\subsection{Availability and affordability of EEE}

Because of the advances in technology and the appetite by the consumer to have more and more, the producers of EEE are always coming up with new and higher quality products. The production of EEE is one of the fastest growing global manufacturing activities (Pinto, 2008). Rapid economic growth, coupled with urbanization and a growing demand for consumer goods, has increased both the consumption and the production of EEE. Developed economies have a higher purchasing power and so have higher chances of buying new products. In struggling economies, EEE and especially ICT and telecommunication devices like mobile phones can change hands several times before they are finally discarded as WEEE. While this is so, in developed economies, once the user feels like the device doesn't serve them well or there is an upgrade of the same equipment, they easily discard it and get a new, upgraded device with ease. Access to ICT's is an indicator to a country's social and economic development (Hameed, nd). In developed economies EEE has a profound impact; they have revolutionized modern living, businesses, governance, communications, transport, health care among others, and so having an 
up-to-date workable EEE is not a luxury but a day to day tool for livelihood. In developing economies, the use of ICTs in its conception and embryonic stages, most countries are still talking about Access to ICTs for their members (Ponelis \& Holmner, 2015).

\section{Conclusion and Recommendation}

Different world economies define e-waste differently depending on who they are, their socioeconomic activities and levels of technological advancement. Advanced economies look at ewaste in its circularity, meaning, they conceive the product with the its end of life in mind, all processes are put into consideration mainly because they are producers of the equipment, they know the parts, the design, materials used and the timeframe with which the EEE will reach its end of life, on the hand emerging economies look at it from a consumers point of view. They look at WEEE as EEE that is voluntarily disposed of once discarded by the user. There is therefore need to understand different contextual definitions for different world economies in order to manage EEE effectively once they reach their EOL.

Disposal is one of e-waste handling steps that have much influence on how people or economies look at WEEE. There is disposal at owner's discretion, and there is some kind of mandatory disposal because systems allow you to dispose of. Fundamental factors affecting disposal include; legal and regulatory framework, the e-waste concept and the availability and affordability of EEE. Developed economies have systems that have matured and are enforced within a geographic location which makes enforcement of the legal instruments manageable, they have had e-waste concept for a long time and so can navigate clearly through the path, and since they manufacture EEE they have access to newer and upgraded EEE affordably. Contrary to that, emerging economies lack a unified legal framework to protect them, any EEE (some substandard or fake) can find its way in the region, the e-waste is a relatively new concept and there may be challenges in availability of affordable high-quality EEE. This also impacts on technology required for management of WEEE.

Studies have indicated that some unscrupulous business people export e-waste illegally from the US to developing nations (US EPA, 2014). Being a world leader, the US should strengthen its policies and laws on e-waste management. It is good that the country recognizes the inherent value of the materials in the EEE nearing its end of life that can be reused, refurbished or recycled to minimize the actual waste that might end up in a landfill or improperly disposed in an unprotected dump site, but there is great need to have federal law to manage e-waste in the country. Every state has been left to handle e-waste the best way they know how unlike in Europe where efforts are coordinated under the EU WEEE Directive. Developing countries have been recipients of the illegal waste imported into their nations. It is therefore high time, they made strict import- export laws to govern what comes into their nations and what goes out of the nations. Developing nations have limited capacity to handle the WEEE they generate internally, having WEEE generated externally into their countries only poses more e-waste management challenges.

Some developing nations have tried to draft regulations on EPR and some are slowly implementing both the EPR and take back systems. Many, have not been able to implement it because they don't have regulations that support its implementation. Experiences from developed countries show that a successful implementation of either EPR or take back system policies requires adequate institutions and sufficient administrative capacity. It's important that developing economies work on their e-waste management tools, so as to facilitate the 
implementation of both EPR and take back system which will eventually make disposal of WEEE successful.

\section{REFERENCES}

Baldé, C. P., Forti, V., Gray, V., Kuehr, R., \& Stegmann, P. (2017). The Global E-waste Monitor 2017: Quantities, Flows, and Resources.

BAN. (2019, August 9). Global Ban on Exporting Hazardous Waste to Developing Countries Becomes Law. Basel Action Network. https://www.ban.org/news/2019/9/8/global-banon-exporting-hazardous-waste-to-developing-countries-becomes-law

Basel Convention. (2011). Where are WEee in Africa? Findings from the Basel Convention Ewaste Af rica Programme. http://www.basel.int/Portals/4/download.aspx?d=UNEPCHW-EWASTE-PUB-WeeAfrica

Business Daily. (2019, July 24). Moi University assembles set of electronic devices. Business Daily. https://www.businessdailyafrica.com/corporate/tech/Moi-University-assemblesset-of-electronic-devices/4258474-5209046-rwjkifz/index.html

Daily Nation. (2013, April 4). Samsung gives Kenya its first TV. Daily Nation. https://www.nation.co.ke/business/Tech/Samsung-to-open-phone-and-TV-assemblyplant-in-Kenya/1017288-1739132-7sdac3z/index.html

Enclude. (2014, December). Final Report: Market Assessment of Modern Off Grid Lighting Systems in Uganda. Lighting Africa. https://www.lightingafrica.org/country/uganda/

EU, W. D. (2012, July 4). Directive 2012/19/EU of the European Parliament and of the C... EUR-Lex [Official Journal of the European Union]. Https://Eur-Lex.Europa.Eu/LegalContent/EN/TXT/PDF/?Uri=CELEX:32012L0019\&from=EN. https://eurlex.europa.eu/legal-content/EN/LSU/?uri=CELEX:32012L0019

Hameed, T. (nd). ICT as an enabler of Socio-Economic Development. 26.

ITU. (2019). The growing challenge of e-waste. https://www.itu.int/en/mediacentre/backgrounders/Pages/e-waste.aspx

Koloseni, D., \& Shimba, F. (2012). E-Waste Disposal Challenges and Remedies: A Tanzanian Perspective. Waste Management - An Integrated Vision. https://doi.org/10.5772/48094

Mbago, F. (2018). E-Waste Disposal in Tanzania. Analysis of Statutory and Regulatory Framework. https://www.grin.com/document/439297

Mmereki, D., Li, B., \& Li'ao, W. (2015). Waste electrical and electronic equipment management in Botswana: Prospects and challenges. Journal of the Air \& Waste Management Association (1995), 65(1), 11-26. https://doi.org/10.1080/10962247.2014.892544

NEMA. (2013). National Environment Management Authority (NEMA)—Draft E-Waste Regulations

[Webpage]. http://www.nema.go.ke/index.php?option=com_content\&view=article\&id=35\&Itemid=1 77

OECD. (2019). Extended producer responsibility. https://www.oecd.org/env/toolsevaluation/extendedproducerresponsibility.htm

Pinto, V. N. (2008). E-waste hazard: The impending challenge. Indian Journal of Occupational and Environmental Medicine, 12(2), 65-70. https://doi.org/10.4103/0019-5278.43263

Ponelis, S. R., \& Holmner, M. A. (2015). ICT in Africa: Enabling a Better Life for All. Information Technology for Development, 21(1), 1-11. https://doi.org/10.1080/02681102.2014.985521 
EACO (2017) Regional E-waste Strategy Retrieved April 3, 2020, from http://www.eaco.int/admin/docs/reports/Regional_E-

waste_Strategy_March_2017_formatted_clean_copy.pdf

Republic of Rwanda. (2016). National E-Waste Management Policy for Rwanda. Republic of Rwanda. $\quad$ http://www.fonerwa.org/sites/default/files/National\%20EWaste\%20Management\%20Policy\%20for\%20Rwanda.pdf

Schumacher, K. A. (2016). Electronic waste management in the U.S.: Practice and policy [Thesis, University of Delaware]. http://udspace.udel.edu/handle/19716/20333

SIMS LTD, S. R. S. (2019). E-Recycler Standards to Consider When Disposing of E-waste. Sims Recycling Solutions. https://www.simsrecycling.com/2019/03/28/e-recycler-standards-toconsider-when-disposing-of-e-waste/

Step Initiative. (2019). What is e-waste? - StEP Initiative [Webpage]. What Is E-Waste? http://www.step-initiative.org/e-waste-challenge.html

Stream Recycling. (2018). History of Electronic Waste Recycling Industry. Stream Recycling. https://www.streamrecycling.com/history-of-electronic-waste-recycling-industry/

UBL. (2020). Automotive Batteries. UGANDA BATTERIES LIMITED. https://www.ublbatteries.ug/automotive-batteries/

UCC. (2018). Draft Report: End of Life (EOL) Management of Communication Equipments (Phase 1). https://www.ucc.co.ug/wp-content/uploads/2017/09/Draft-report-Study-on-theEnd-of-Life-Management-EoL-of-Communications-Equipment-PHASE-I-Copy-pdf

Unified Compliance. (2020). What is a Definition? Unified Compliance. https://www.unifiedcompliance.com/education/how-to-write-definitions/

US EPA, O. (2014). Cleaning Up Electronic Waste (E-Waste) [Overviews and Factsheets]. US EPA. https://www.epa.gov/international-cooperation/cleaning-electronic-waste-e-waste

Vaccari, M., Vinti, G., Cesaro, A., Belgiorno, V., Salhofer, S., Dias, M. I., \& Jandric, A. (2019). WEEE Treatment in Developing Countries: Environmental Pollution and Health Consequences-An Overview. International Journal of Environmental Research and Public Health, 16(9). https://doi.org/10.3390/ijerph16091595

Veerasamy, V. (2013). The Importance of Good Definitions (Or: How To Think Clearly). Wordof-Mouth and Referral Marketing Blog. https://www.referralcandy.com/blog/importanceof-good-definitions/

WHO. (2020). WHO | Electronic waste. WHO; World Health Organization. http://www.who.int/ceh/risks/ewaste/en/

This is an open-access article published and distributed under the terms and conditions of the $(\mathrm{coc}) \mathrm{EY}$ Creative Commons Attribution 4.0 International License of United States unless otherwise stated. Access, citation and distribution of this article is allowed with full recognition of the authors and the source.

Authors seeking to publish with an International Peer Reviewed Journal should consider https://www.ijcab.org/ by writing to the Editor at editor@ijcab.org. The articles must be quality and meet originality test. 